\title{
Case 2: Early Neonatal Seizures
}

\author{
Deepali Handa, MD ${ }^{\star}$, Nancy Barclay, NNP-BC, MSN ${ }^{\star}$, David Rehrauer, NNP-BC, MSN ${ }^{\star}$, and \\ Satyan Lakshminrusimha, MD* \\ *Department of Pediatrics, University at Buffalo, State University of New York and Neonatal \\ Intensive Care Unit, Women and Children's Hospital of Buffalo, NY
}

\section{Presentation}

A $40^{3} / 7$-week, 3,660-g, appropriate for gestational age girl presents with early-onset seizures in the nursery. The mother is a 28 -year-old, primigravida woman with an uncomplicated pregnancy except for a low amniotic fluid index in the third trimester. The infant was born by spontaneous vaginal delivery 5 hours after rupture of membranes. Approximately 2 hours after birth, the infant is noticed to have twitching of extremities by the lactation consultant. The infant is transferred to the newborn nursery and on admission is noted to have some duskiness and jitteriness of the upper extremities that subside within a minute. Vitals signs are stable at the time, and she is kept under observation. At $3 \frac{1}{2} 2$ hours after birth, she has a 14-minute seizure activity that manifests as left eye and facial twitching, drooling from the mouth, constant blinking, repetitive twitching of upper and lower extremities, and the entire torso posturing to the right. The patient is given $20 \mathrm{mg} / \mathrm{kg}$ of phenobarbital at the time. The bedside dextrose level is $72 \mathrm{mg} / \mathrm{dL}$. An intravenous catheter is placed, and blood gas analysis, basic metabolic profile, complete blood cell count with differential count, and a blood culture are performed. Ampicillin and gentamicin are administered empirically along with dextrose $10 \%$ at $60 \mathrm{~mL} / \mathrm{kg} / \mathrm{d}$. Laboratory results are significant for a sodium level of $119 \mathrm{mEq} / \mathrm{L}(119 \mathrm{mmol} / \mathrm{L})$ and a chloride level of $88 \mathrm{mEq} / \mathrm{L}(88 \mathrm{mmol} / \mathrm{L})$. A subsequent point-of-care blood test confirms hyponatremia. The fluids are switched to $0.9 \%$ saline at that time, and an immediate request is made to have the maternal basic metabolic profile evaluated. Maternal blood work reveals a sodium level of $122 \mathrm{mEq} / \mathrm{L}(122 \mathrm{mmol} / \mathrm{L})$ and a chloride level of $93 \mathrm{mEq} / \mathrm{L}(93 \mathrm{mmol} / \mathrm{L})$. The infant is transferred to the regional perinatal center for further management.

Once in the neonatal intensive care unit, the infant is fluid restricted to $40 \mathrm{~mL} / \mathrm{kg} / \mathrm{d}$ with $14 \%$ dextrose in $0.9 \%$ saline solution. Subsequent electrolyte analysis reveals that the serum sodium level has further decreased to $116 \mathrm{mEq} / \mathrm{L}$ (115 mmol/L). Sodium correction is performed with $3 \%$ sodium chloride at that time, and the level increases to $120 \mathrm{mEq} / \mathrm{L}$ (120 $\mathrm{mmol} / \mathrm{L})$ within an hour and then to $125 \mathrm{mEq} / \mathrm{L}(125 \mathrm{mmol} / \mathrm{L})$ by 15 hours. During the next 3 days, fluid volume and electrolyte composition are adjusted to achieve a gradual increment in serum sodium. Enteral feedings are initiated on day 2, and the infant is discharged home on day 4 with serum sodium levels of 138 to $140 \mathrm{mEq} / \mathrm{L}(138-140 \mathrm{mmol} / \mathrm{L})$. Head magnetic

\section{AUTHOR DISCLOSURE}

Dr Handa, Ms Barclay, and Mr Rehrauer have disclosed no financial relationships relevant to this article. 
resonance imaging and electroencephalography results are normal, and the blood culture result is negative. No further seizures are seen during the hospital course or after discharge at home.

A detailed maternal history reveals that the mother had increased her fluid intake at home because of a low AFI. The mother continued an intake of 4 to $5 \mathrm{~L}$ of plain water during 14 hours of labor. She expressed headache, intense fatigue, and weakness associated with watery stools through her labor and postpartum period. Admission electrolytes were not measured. After she is found to be hyponatremic, her fluid intake is restricted, and she is placed on a saline drip at $60 \mathrm{~mL} / \mathrm{h}$. Her hyponatremia resolves during the next few hours without any seizure activity.

\section{Discussion}

An infant who presents with seizures in the initial hours after delivery, after undergoing a normal birth process, poses an interesting conundrum. Quick response and investigation are imperative in the initial medical treatment.

The incidence of neonatal seizures is reported to be approximately $0.1 \%$ to $0.5 \%$, and seizures are more common in the first week after birth than any other time. Hypoxic ischemic encephalopathy, focal infarcts, intracranial hemorrhage, cerebral dysgenesis, transientmetabolic disturbances (such as hypoglycemia, hypocalcemia, and hypomagnesemia), infectious meningitis or encephalitis, and inborn errors of metabolism are the common culprits causing neonatal seizures. (1) Hyponatremia does not rank high in the hierarchy of causes for early-onset seizures because the infant has so far not been exposed to hypo-osmolar feeds or fluids. The most common cause of fetal or neonatal hyponatremia is maternal hyponatremia because fetal sodium levels mimic maternal levels. This is usually a result of water intoxication, which could be secondary to multiple factors (Figure 1). Ingestion of excessive electrolyte free water during labor is not a common cause of fetal hyponatremia, although some cases have been reported. (2)

Hyponatremia is defined as a sodium level less than $130 \mathrm{mEq} / \mathrm{L}(<130 \mathrm{mmol} / \mathrm{L})$. The threshold for seizure activity secondary to hyponatremia is unique to each patient; however, symptoms are more likely at less than $125 \mathrm{mEq} / \mathrm{L}(<125 \mathrm{mmol} / \mathrm{L})$. Studies in newborn puppies suggest that even a moderate degree of hyponatremia might cause a significant increase in total extracellular and intracellular brain water and decrease in brain tissue sodium content within a short period. The results of these fluid shifts may cause brain edema and subsequent cerebral symptoms, such as lethargy, coma, apnea, cyanotic episodes, and seizures. (3) Seizures are an advanced sign of hyponatremic encephalopathy and need emergency treatment. A recent review focusing on the treatment of hyponatremic encephalopathy in children recommends giving a $2-\mathrm{mL} / \mathrm{kg}$ bolus of $3 \%$ sodium during 10 minutes in symptomatic hyponatremia. (4) Additional boluses can be given 1 to 2 times until symptoms improve, with the goal of correction up to 5 to $6 \mathrm{mEq} / \mathrm{L}(5-6 \mathrm{mmol} / \mathrm{L})$ in the first 1 to 2 hours. The recommendation is not to exceed correction of 15 to $20 \mathrm{mEq} / \mathrm{L}$ (15-20 $\mathrm{mmol} / \mathrm{L}$ ) in the first 48 hours. The review also concludes that patients with acute hyponatremia are not at significant risk for developing cerebral demyelination on correction 
following the above protocol. Patients with chronic hyponatremia with additional risk factors, such as liver disease, malnutrition, and hypoxia, and those corrected rapidly with an increase in serum sodium of greater than $25 \mathrm{mEq} / \mathrm{L}(>25 \mathrm{mmol} / \mathrm{L}$ ) in the first 24 to 48 hours are at highest risk for developing cerebral demyelination.

The clinical evidence regarding long-term neurodevelopmental prognosis in neonates with hyponatremic seizures is sparse. Studies in animal models with neonatal seizures suggest impaired cognition (mainly visuospatial learning and short-and long-term memory), altered behavior, increased anxiety, and association with epileptogenesis. (5) Tekgul et al (1) observed that the association between seizure origin and outcome was strong, with global hypoxemia ischemia and cerebral dysgenesis associated with the worst outcomes and transient metabolic disturbances associated with milder delays. In view of the seizure-related potential brain damage in neonates, prompt diagnosis and treatment are imperative.

As per the latest American Congress of Obstetricians and Gynecologists committee opinion, the oral intake of modest amounts of clear liquids may be allowed for patients with uncomplicated labor. The patients are usually recommended to stay well hydrated without specific recommendations for electrolyte-suffused fluids. As seen above, intake of fluids without electrolytes in the presence of increased gastrointestinal losses puts the maternal infant dyad at risk for electrolyte imbalances and possibly seizures. More awareness of this potential complication of seemingly harmless overhydration during labor is warranted.

Formulating the appropriate differential diagnosis early on, initiating laboratory work, and implementing the hyponatremia correction were key elements in the expeditious management in this case. Pediatricians and neonatologists in the community should be aware of this potential but uncommon cause, which if treated early and appropriately would impart a good long-term prognosis for their patients.

\section{Acknowledgments}

Dr Lakshminrusimha has disclosed he is a consultant for NICHD grant 5R01HDO72929-04. This commentary does not contain discussion of unapproved/investigative use of a commercial product/device.

\section{References}

1. Tekgul H, Gauvreau K, Soul J, et al. The current etiologic profile and neurodevelopmental outcome of seizures in term newborn infants. Pediatrics. 2006; 117(4):1270-1280. [PubMed: 16585324]

2. Johansson S, Lindow S, Kapadia H, Norman M. Perinatal water intoxication due to excessive oral intake during labour. Acta Paediatr. 2002; 91(7):811-814. [PubMed: 12200908]

3. Ophir E, Solt I, Odeh M, Bornstein J. Water intoxication-a dangerous condition in labor and delivery rooms. Obstet Gynecol Surv. 2007; 62(11):731-738. [PubMed: 17925046]

4. Moritz ML, Ayus JC. New aspects in the pathogenesis, prevention, and treatment of hyponatremic encephalopathy in children. Pediatr Nephrol. 2010; 25(7):1225-1238. [PubMed: 19894066]

5. Thibeault-Eybalin M-P, Lortie A, Carmant L. Neonatal seizures: do they damage the brain? Pediatr Neurol. 2009; 40(3):175-180. [PubMed: 19218030] 


\section{Lessons for the Clinician}

- Hyponatremia, although uncommon, should be considered as cause of early neonatal seizures because emergent recognition and treatment is necessary for good longterm prognosis.

- Monitoring electrolytes is an important step in diagnosing the cause of neonatal seizures, in addition to neurologic workup.

- Excess maternal free water consumption during labor is an important cause of neonatal hyponatremia. 


\section{American Board of Pediatrics Neonatal-Perinatal Content Specifications}

- Know the etiology of electrolyte abnormalities in the neonate.

- Recognize the clinical and laboratory manifestations of electrolyte abnormalities in the neonate.

- Understand the differential diagnosis and evaluation of neonatal seizures. 


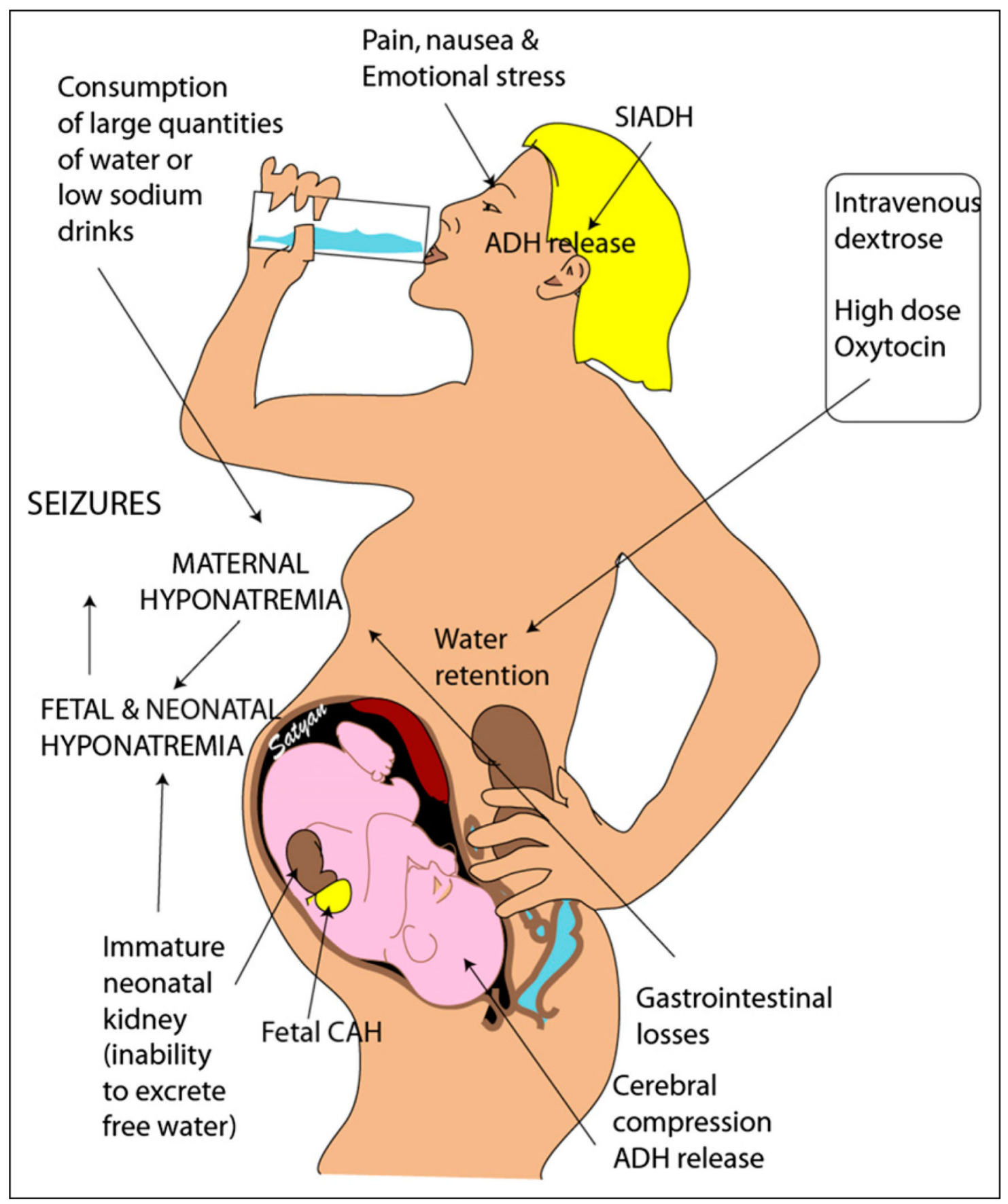

Figure 1.

Causes of maternal and fetal or neonatal hyponatremia. 